\title{
Molecular evidence of Pleistocene bidirectional faunal exchange between Europe and the Near East: the case of the bicoloured shrew (Crocidura leucodon, Soricidae)
}

\author{
S. DUBEY, ${ }^{*}$ J.-F. COSSON, $\uparrow$ V. VOHRALÍK, + B. KRYŠTUFEK, $\S$ E. DIKER \& P. VOGEL* \\ *Department of Ecology and Evolution, University of Lausanne, Lausanne, Switzerland \\ $\uparrow$ Centre de Biologie et de Gestion des Populations (CBGP), INRA-EFPA, Campus International de Baillarguet, Montferrier/Lez cedex, France \\ \$Department of Zoology, Charles University, Viničná, Prague, Czech Republic \\ $\S$ Science and Research Centre of Koper, University of Primorska, Garibaldijeva, Koper, Slovenia \\ -Department of Biology, Faculty of Art and Sciences, Trakya University, Edirne, Turkey
}

Keywords:

apolipoprotein B gene;

Crocidura leucodon;

cytochrome $b$ gene;

phylogeography.

\begin{abstract}
We sequenced $1077 \mathrm{bp}$ of the mitochondrial cytochrome $b$ gene and $511 \mathrm{bp}$ of the nuclear Apolipoprotein B gene in bicoloured shrew (Crocidura leucodon, Soricidae) populations ranging from France to Georgia. The aims of the study were to identify the main genetic clades within this species and the influence of Pleistocene climatic variations on the respective clades. The mitochondrial analyses revealed a European clade distributed from France eastwards to north-western Turkey and a Near East clade distributed from Georgia to Romania; the two clades separated during the Middle Pleistocene. We clearly identified a population expansion after a bottleneck for the European clade based on mitochondrial and nuclear sequencing data; this expansion was not observed for the eastern clade. We hypothesize that the western population was confined to a small Italo-Balkanic refugium, whereas the eastern population subsisted in several refugia along the southern coast of the Black Sea.
\end{abstract}

\section{Introduction}

The impact of Pleistocene climatic fluctuations on European biota is well documented. Studies of mitochondrial DNA markers reveal general patterns involving southern refugia and northern recolonization routes, as a modification of genetic diversity of terrestrial biota throughout the Holartic (Hewitt, 2000, 2004a,b). Populations were isolated in different glacial refugia by barriers such as mountains and seas, leading to various recolonization patterns (e.g. Taberlet et al., 1998; Hewitt, 1999). Widely accepted refugia include the Iberian Peninsula in the west and the Italo-Balkanic region in the east (e.g. Thorpe, 1984; Ferris et al., 1993, 1998; Dumolin-Lapegue et al., 1997; Santucci et al., 1998; Taberlet et al., 1998;

Correspondence: Sylvain Dubey, Département d'Ecologie et d'Evolution, Bâtiment du Biophore, Université de Lausanne, 1015 Lausanne, Switzerland.

Tel.: +41 21692 4163; fax: +41 21692 4165;

e-mail: sylvain.dubey@unil.ch

Address from September 2007: Shine Laboratory, School of Biological

Sciences, University of Sydney, Sydney, NSW 2006, Australia.
Dubey et al., 2006); however, a number of phylogeographical studies of various taxa have revealed an additional pattern of colonization of Europe by populations originating from eastern areas such as the Caucasus, southern Urals and western Asia (Cooper et al., 1995; Bilton et al., 1998; Nesbo et al., 1999; Palme \& Vendramin, 2002; Seddon et al., 2002; Michaux et al., 2004; Culling et al., 2006; Dubey et al., 2006). This pattern of post-glacial recolonization appears to be more common than previously suspected and probably affected a large range of taxa.

With regard to population dynamics, few studies have detailed the impact of Pleistocene climatic oscillations, e.g. the dating of population expansions and identifying differences in patterns among clades of different geographical origin (Michaux et al., 2004; Brändli et al., 2005; Culling et al., 2006; Dubey et al., 2006; Koch et al., 2006; Marmi et al., 2006; Vörös et al., 2006; Dubey et al., 2007a). In the same way, the majority of previous studies are based solely on mitochondrial DNA, whereas the inclusion of uniparentally and biparentally inherited markers present in nuclear genomes can enhance our 
understanding of population history (Brändli et al., 2005; Dubey et al., 2006).

In the present study, we focused on the bicoloured shrew, Crocidura leucodon (Hermann, 1780), which is a strictly western Eurasian species, distributed from France to central and southern Europe to Turkey and Georgia. This species seems to be an interesting candidate for a phylogeographical study, as Vogel et al. (2003), based on only two samples, from Switzerland and Turkey, noted a substantial Kimura 2-paramters genetic distance of 3.8\% between them for the cytochrome $b$ gene. In addition, Poulakakis et al. (2005) analysed three Greek samples (from Peloponnesus and Lesbos) obtained from owl pellets, based on the same gene, promoting such material as usable for phylogeographical studies, without giving any information concerning the distances between haplotypes. Nevertheless, the intraspecific genetic distances were considered low.

We tested (i) in which way the Bosphorus strait has isolated the European and Near East populations and (ii) in which way the Pleistocene climatic fluctuations have had different impacts on the western and eastern populations, such as bottleneck effects. To resolve these questions, we analysed sequence data from mitochondrial and nuclear markers (cytochrome $b$ and apolipoprotein $\mathrm{B}$ ) and considered the molecular clock.

\section{Materials and methods}

\section{Sampling}

We analysed 60 samples of C. leucodon collected from France to Georgia (Fig. 1 and Table 1), three other Eurasian crocidurine taxa, and as an out-group a soricine, Sorex minutus. This set of samples (Table 1) included material from the collections of Lausanne (IZEA), Switzerland; Prague (DZCU), Czech Republic and Ljubljana (PMS), Slovenia. Some sequences were taken from Ohdachi et al. (2004); Fontanillas et al. (2005) and Dubey et al. (2006). We also used samples from Poulakakis et al. (2005) that were treated separately.

\section{DNA extraction and amplification of cytochrome $b$ and apolipoprotein $B$ genes}

Samples (livers) from IZEA collection were first frozen in the field in liquid nitrogen and kept for several years at $-70{ }^{\circ} \mathrm{C}$ before being stored in ethanol until DNA extraction. Samples from the other collections were directly stored in ethanol. DNA extraction was carried out using the QIA Amp DNA Mini Kit (Qiagen, Valencia, PA, USA). Double-stranded DNA amplifications of the mitochondrial cytochrome $b$ gene $(c y t-b)$ were performed with the primer pairs L14724/H15149, C1/C2, C3/H15915 and L14724/H15915 (Irwin et al., 1991; Dubey et al., 2006). Amplification of the apolipoprotein $\mathrm{B}(A p \circ B)$ nuclear genes was performed using the primer pairs ApoBf/ApoBr (Dubey et al., 2007b). Amplification conditions for the $A p o B$ consisted of 40 cycles of 45 s denaturation at $94{ }^{\circ} \mathrm{C}$, $45 \mathrm{~s}$ annealing at $50{ }^{\circ} \mathrm{C}$ and $90 \mathrm{~s}$ extension at $72{ }^{\circ} \mathrm{C}$; for the $c y t-b$, the conditions of Dubey et al. (2006) were used.

The PCR products were checked on a $1 \%$ agarose gel and then purified using the QIAquick PCR Purification Kit (QIAgen) following the manufacturer's instructions. DNA sequencing was performed in a total volume of $10 \mu \mathrm{L}$ containing $1-3 \mu \mathrm{L}$ of amplified PCR product, $1 \mu \mathrm{L}$ of $10 \mu \mathrm{M}$ primer, and $4 \mu \mathrm{L}$ of ABI PRISM ${ }^{\mathrm{TM}}$ Dye Terminator 1 (Perkin-Elmer, Boston, MA, USA). Sequence reactions were visualized on an $\mathrm{ABI} 3100$ genetic analyser (Applied Biosystems, Foster City, CA, USA).
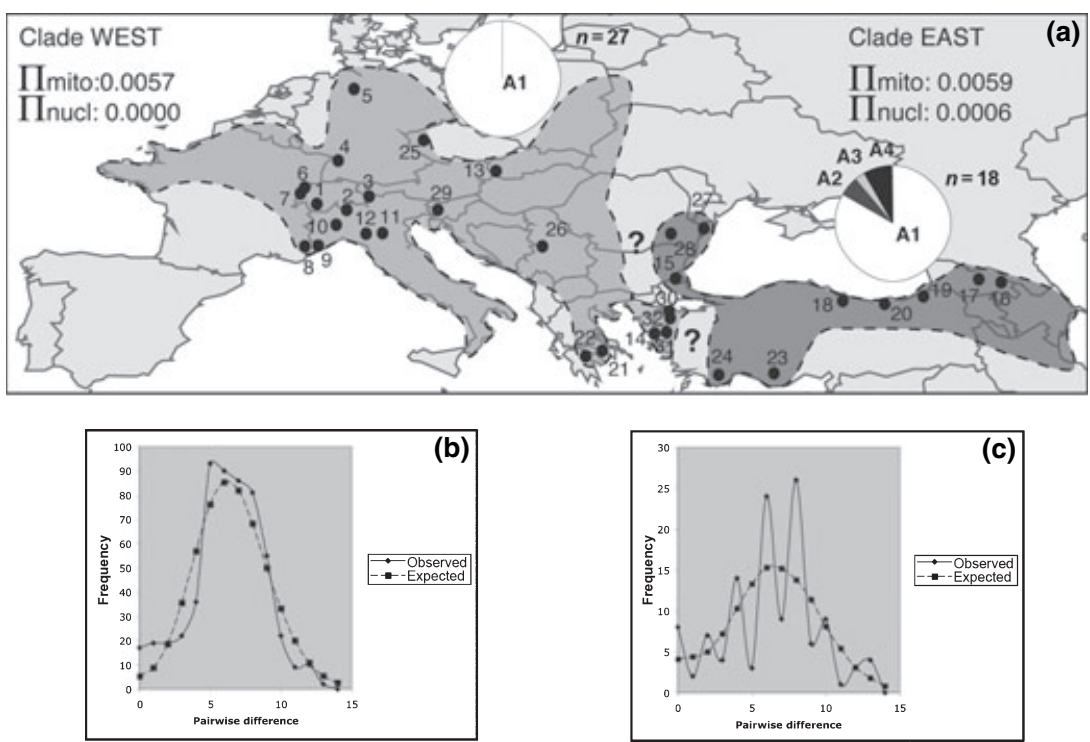

Fig. 1 (a) Location of analysed samples, tentative distribution of mitochondrial clades (grey areas), allelic frequencies of nuclear genes (cheese), and nucleotide diversity of mitochondrial and nuclear gene; (b,c) Observed (solid line) and expected (dottedline) mismatch distributions for a sudden expansion of the western and eastern clades, respectively. 
Table 1 Details of samples used in this study: species, samples location, collection, location on map (Fig. 1), cyt- $b$ Id. Code, accession number of $c y t-b$ sequences, and $A p o B$ alleles.

\begin{tabular}{|c|c|c|c|c|c|}
\hline Species & Samples location & Coll. code & $\begin{array}{l}\text { Number on } \\
\text { the map }\end{array}$ & $\begin{array}{l}\text { Cyt-b } \\
\text { Id. code }\end{array}$ & $\begin{array}{l}\text { Accession (cyt-b) and } \\
\text { Apob allele }\end{array}$ \\
\hline Sorex minutus & Champmartin, $\mathrm{CH}$ & IZEA 7622 & I & / & DQ630379/- \\
\hline Crocidura suaveolens & Fulophasa, HU & Dubey et al. (2006) & / & / & AY843451/- \\
\hline Crocidura russula & Vaud, $\mathrm{CH}$ & Fontanillas et al. (2005) & / & / & AY769264/- \\
\hline Crocidura lasiura & Ussurisk, RU & Ohdachi et al. (2004) & / & / & AB077071/- \\
\hline Crocidura leucodon & Visp, $\mathrm{CH}$ & IZEA 7553 & 1 & $\mathrm{CH} 1$ & DQ994744/A1 \\
\hline Crocidura leucodon & Réchy, CH & IZEA 7552 & 1 & $\mathrm{CH}_{2}$ & DQ994745/A1 \\
\hline Crocidura leucodon & Brigerbad, $\mathrm{CH}$ & IZEA 2951 & 1 & $\mathrm{CH} 3$ & DQ994747/- \\
\hline Crocidura leucodon & Raron, $\mathrm{CH}$ & IZEA 7532 & 1 & $\mathrm{CH} 4$ & DQ994746/- \\
\hline Crocidura leucodon & Réchy, $\mathrm{CH}$ & IZEA 5590 & 1 & $\mathrm{CH} 9$ & DQ994794/- \\
\hline Crocidura leucodon & Brigerbad, $\mathrm{CH}$ & IZEA 7526 & 1 & 1 & $-/ A 1$ \\
\hline Crocidura leucodon & Gordevio, $\mathrm{CH}$ & IZEA 5965 & 2 & $\mathrm{CH} 5$ & DQ994748/- \\
\hline Crocidura leucodon & Gordevio, $\mathrm{CH}$ & IZEA 5963 & 2 & $\mathrm{CH} 6$ & DQ994749/A1 \\
\hline Crocidura leucodon & Quartino, $\mathrm{CH}$ & IZEA 5455 & 2 & $\mathrm{CH} 7$ & DQ994750/A1 \\
\hline Crocidura leucodon & Grison, $\mathrm{CH}$ & IZEA 9013 & 3 & $\mathrm{CH} 8$ & DQ994785/A1 \\
\hline Crocidura leucodon & Karlsruhe, DE & IZEA 5441 & 4 & DE5 & DQ994795/A1 \\
\hline Crocidura leucodon & Rendsburg, DE & IZEA 7835 & 5 & DE1 & DQ994761/- \\
\hline Crocidura leucodon & Rendsburg, DE & IZEA 7836 & 5 & DE2 & DQ994762/- \\
\hline Crocidura leucodon & Rendsburg, DE & IZEA 7837 & 5 & DE3 & DQ994763/A1 \\
\hline Crocidura leucodon & Rendsburg, DE & IZEA 7838 & 5 & DE4 & DQ994764/- \\
\hline Crocidura leucodon & Mignouillard, FR & IZEA 9006 & 6 & FR4 & DQ994780/A1 \\
\hline Crocidura leucodon & Mignouillard, FR & IZEA 9002 & 6 & FR5 & DQ994781/A1 \\
\hline Crocidura leucodon & Chapelle, FR & IZEA 9003 & 7 & FR2 & DQ994779/A1 \\
\hline Crocidura leucodon & Chapelle, FR & IZEA 9005 & 7 & FR3 & DQ994782/A1 \\
\hline Crocidura leucodon & St-Martin, FR & IZEA 9008 & 8 & FR1 & DQ994783/A1 \\
\hline Crocidura leucodon & St-Etienne, FR & IZEA 9009 & 9 & FR6 & DQ994784/A1 \\
\hline Crocidura leucodon & Vercelli, IT & IZEA 7948 & 10 & IT1 & DQ994767/- \\
\hline Crocidura leucodon & Vercelli, IT & IZEA 7946 & 10 & IT2 & DQ994768/- \\
\hline Crocidura leucodon & Vercelli, IT & IZEA 7952 & 10 & IT3 & DQ994769/- \\
\hline Crocidura leucodon & Serramazoni, IT & IZEA 5662 & 11 & IT4 & DQ994770/A1 \\
\hline Crocidura leucodon & Serramazoni, IT & IZEA 5649 & 11 & IT5 & DQ994771/- \\
\hline Crocidura leucodon & Serramazoni, IT & IZEA 5663 & 11 & IT6 & DQ994772/A1 \\
\hline Crocidura leucodon & Piacenza, IT & IZEA 7517 & 12 & IT7 & DQ994773/A1 \\
\hline Crocidura leucodon & Bratislava, SK & IZEA 5728 & 13 & SK1 & DQ994765/- \\
\hline Crocidura leucodon & Bratislava, SK & IZEA 5723 & 13 & SK2 & DQ994766/A1 \\
\hline Crocidura leucodon & Lesbos, GR & IZEA 4153 & 14 & GR1 & DQ994777/A1 \\
\hline Crocidura leucodon & Lesbos, GR & IZEA 3929 & 14 & GR2 & DQ994778/A1 \\
\hline Crocidura leucodon & Lesbos, GR & Poulakakis et al., 2005 & 14 & - & AY452165/- \\
\hline Crocidura leucodon & Burgas, BG & IZEA 8059 & 15 & $\mathrm{BG} 1$ & DQ994774/A1/A2 \\
\hline Crocidura leucodon & Burgas, BG & IZEA 8060 & 15 & BG2 & DQ994775/A1 \\
\hline Crocidura leucodon & Burgas, BG & IZEA 8063 & 15 & BG3 & DQ994776/A1 \\
\hline Crocidura leucodon & Burgas, BG & IZEA 8059 & 15 & - & $-/ A 1 / A 2$ \\
\hline Crocidura leucodon & Alazani, GE & IZEA 23629 & 16 & GE1 & DQ994756/A1/A4 \\
\hline Crocidura leucodon & Alazani, GE & IZEA 23635 & 16 & GE2 & DQ994757/A4 \\
\hline Crocidura leucodon & Alazani, GE & IZEA 23613 & 16 & GE3 & DQ994758/A1 \\
\hline Crocidura leucodon & Dusheti, GE & IZEA 2880 & 17 & GE4 & DQ994760/A1/A3 \\
\hline Crocidura leucodon & Cakalli, TR & IZEA 6064 & 18 & TR1 & DQ994751/A1 \\
\hline Crocidura leucodon & Rize, TR & IZEA 6045 & 19 & TR2 & DQ994752/- \\
\hline Crocidura leucodon & Rize, TR & IZEA 6049 & 19 & TR3 & DQ994753/A1 \\
\hline Crocidura leucodon & Rize, TR & IZEA 6047 & 19 & TR4 & DQ994754/A1 \\
\hline Crocidura leucodon & Rize, TR & IZEA 6046 & 19 & TR5 & DQ994755/A1 \\
\hline Crocidura leucodon & Altindere, TR & IZEA 6039 & 20 & TR6 & DQ994759/A1 \\
\hline Crocidura leucodon & Altindere, TR & IZEA 6038 & 20 & TR7 & DQ994796/- \\
\hline Crocidura leucodon & Altindere, TR & IZEA 6044 & 20 & - & $-/ A 1$ \\
\hline Crocidura leucodon & Yellibeli, Kar., TR & DZCU TU-1179 & 23 & TR8 & DQ994787/A1 \\
\hline Crocidura leucodon & Çiğlikara, Ant., TR & DZCUTU-1195 & 24 & TR9 & DQ994786/A1 \\
\hline Crocidura leucodon & Karlovy Vary, CZ & DZCU 01400 & 25 & - & $-/ \mathrm{A} 1$ \\
\hline Crocidura leucodon & Karlovy Vary, CZ & DZCU 01399 & 25 & $\mathrm{CZ1}$ & DQ994788/A1 \\
\hline
\end{tabular}


Table 1 (Continued).

\begin{tabular}{|c|c|c|c|c|c|}
\hline Species & Samples location & Coll. code & $\begin{array}{l}\text { Number on } \\
\text { the map }\end{array}$ & $\begin{array}{l}\text { Cyt-b } \\
\text { ld. code }\end{array}$ & $\begin{array}{l}\text { Accession }(c y t-b) \text { and } \\
\text { Apob allele }\end{array}$ \\
\hline Crocidura leucodon & Karlovy Vary, CZ & DZCU 01398 & 25 & CZ2 & DQ994789/A1 \\
\hline Crocidura leucodon & Mt. Cer, SE & PMS 7391 & 26 & SE1 & DQ994790/A1 \\
\hline Crocidura leucodon & Cataloi, RO & IZEA 8160 & 27 & $\mathrm{RO} 1$ & DQ994791/A1 \\
\hline Crocidura leucodon & Slobozia, RO & IZEA 8170 & 28 & $\mathrm{RO} 2$ & DQ994792/A1 \\
\hline Crocidura leucodon & Vrhnika, SI & PMS Slo 1 & 29 & $\mathrm{Sl1}$ & DQ994793/A1 \\
\hline Crocidura leucodon & Katranci-Biga, TR & 2003.131 & 30 & TR10 & EF417543/A1 \\
\hline Crocidura leucodon & Özbek, İzmir, TR & 2003.199 & 31 & TR11 & EF417544/A1 \\
\hline Crocidura leucodon & Terzialan-Çan., TR & 2003.217 & 32 & TR12 & EF417545/A1 \\
\hline Crocidura leucodon & Parnitha, GR & Poulakakis et al., 2005 & 21 & - & AY452166/- \\
\hline Crocidura leucodon & Stymfalia, GR & Poulakakis et al., 2005 & 22 & - & AY452176/- \\
\hline
\end{tabular}

BG, Bulgaria; CZ, Czech Republic; DE, Germany; FR, France; GE, Georgia; GR, Greece; HU, Hungary; IT, Italy; RU, Russia; SE, Serbia; SK, Slovak Republic; SI, Slovenia; CH, Switzerland; TR, Turkey.

\section{Phylogenetic methods}

Nucleotide sequences of $c y t-b$ and $A p o B$ genes were edited with Sequence Navigator (Parker, 1997) and manually aligned. Two methods of phylogenetic analyses were carried out for cyt- $b$, using PAUP*version $4.0 \mathrm{~b} 10$ PPC (Swofford, 1998). Tests were conducted on the complete fragment (1077 bp), all codon positions were used, and trees were rooted using sequences of $S$. minutus (DQ630379). A Neighbour Joining (NJ) tree was constructed using the general time reversible (GTR; Rodriguez et al., 1990) genetic distance, which was selected previously using MODELTEST 3.06 according to the protocol of Posada \& Crandall (1998). The Parsimony analyses (MP) were performed using the following options: heuristic search, stepwise-addition of sequences, 10 replicates of random addition of taxa and TBR branch swapping (Swofford, 1998); all codon positions were equally weighted. Bootstrap support values were obtained with 1000 pseudo-replicates and 10 random replicates of stepwise-addition sequences. Fast maximum likelihood (ML) heuristic searches and bootstrap analyses (1000 replicates) were performed using PнумL (Guindon \& Gascuel, 2003) with a GTR model.

\section{Nucleotide diversity and genetic structure}

The nucleotide diversities $(\pi)$ of $c y t-b$ and $A p o B$ and the population genetic structure for $c y t-b$ (analysis of molecular variance, Amova) were estimated using Arlequin version 2.0 Software (Schneider, 2000). Amova was performed at two different hierarchical levels: among clades and within clades.

\section{Molecular clock}

The molecular clock hypothesis was tested following the method of Posada \& Crandall (1998). Estimation of divergence time from the molecular data was performed according to the calibration developed for $c y t-b$ in
Soricidae by Fumagalli et al. (1999), based on an estimate of 20 Myr for the split between the Soricinae and the Crocidurinae and on the number of third-position transversions observed. Nevertheless, it could not be used directly because of the low number of third-position transversions observed at a specific level within the family. Thus, we used the calibration of Dubey et al. (2006), based on the previous study that allowed a better estimate because of the use of a ML distance including all the codon positions with a divergence rate of $0.057 \mathrm{ML}$ distance $\mathrm{Myr}^{-1}$ (95\% CI: 0.044-0.070).

\section{Isolation with migration}

We used the 'isolation with migration' (or IM, Nielsen $\delta$ Wakeley, 2001) model to date the divergence between populations of both sides of the Marmara Sea within each clade. As suggested by Hey (2007), we started the simulations using a burn-in of 100000 steps followed by a $1 / 2 \mathrm{~h}$ run with maximum values for theta, $m$ and $t$ arbitrary set to 10 and the $-\mathrm{Jl}$ run option. From there, appropriate values for priors were chosen. In each following run, plots of parameter trend lines were systematically consulted for assessing how well the Markov chain was exploring the parameter space. Convergence by the Markov chain simulations was assessed by monitoring three independent chains, and by assessing the autocorrelation of parameter values over the course of each run. Individual simulations were run for 10 million updates or more. For each of the demographic parameters we recorded the marginal density. The peaks of the resulting distributions were taken as estimates of the parameters and the $90 \%$ highest posterior density (HPD) interval was taken for the credibility intervals. Estimates with IM are scaled by the overall neutral mutation rate per gene per generation. We assigned an inheritance scalar of 0.25 as usual for mtDNA and assumed 1 year per generation. To convert parameter estimates to time scale units, we used the average rate of evolution for the $c y t-b$ gene in Crocidura species from 
Dubey et al. (2006), corresponding to 3.07E-5 (95\% CI: 2.37E-5-3.77E-5) mutation events/locus/year.

\section{Expansion time}

To test the hypothesis of recent population growth from a low-diversity founder population within the different clades, several tests were performed for $c y t-b$. We used three methods implemented in Arlequin version 2.0 (Schneider, 2000). The first method, Fu's (1997) $F_{S}$ statistic, tests the probability of having no fewer than the number of observed alleles in the sample given that $\theta$ (heterozygosity per sites) $=\pi$. This statistic tends to be negative when there is an excess of recent mutations (or rare alleles). The second method, Tajima's (1989) $D$ statistic, tests the null hypothesis that two estimates of the neutral mutation parameter, one derived from the average number of pairwise nucleotide differences and the other based on the number of segregating sites in the sample, are equal. In the third test, pairwise mismatch distributions among individuals were plotted and tested for goodness-of-fit to a model of sudden expansion using parametric bootstrapping with 1000 replicates (Schneider $\&$ Excoffier, 1999). Expansion time after the bottleneck was estimated from the mismatch distribution $(\tau)$ (Rogers, 1995) and uncorrected distances $(p)$. Evolutionary rate for uncorrected $(p)$ distance was estimated using the molecular clock developed by Fumagalli et al. (1999) with a divergence rate of 0.061 uncorrected distance (p) $\mathrm{Myr}^{-1}$ (95\% CI: 0.054-0.069).

\section{Results}

\section{Cytochrome $b$ gene}

The 60 C. leucodon samples showed 41 different haplotypes of $1077 \mathrm{bp}$ and contained 366 variable sites, of which 218 were parsimony-informative. No insertions or deletions were observed. As the three phylogenetic methods gave identical arrangements of the main branches, the relationship between haplotypes is given only for the ML analysis in Fig. 2.

The C. leucodon samples formed a monophyletic unit (all bootstrap values of $100 \%$ ), well differentiated from the other Eurasian species (Fig. 2). Within this unit, two major and strongly supported clades were found (all bootstrap values $\geq 80 \%$ ).

Clade I (western clade) included European samples from the Czech Republic, France, Germany, Greece (Lesbos), Italy, Serbia, Slovakia, Slovenia, Switzerland, and samples from north-western Anatolia, Turkey. Clade II (eastern clade) included the European samples from Bulgaria and Romania and the samples from Georgia and Anatolia (with the exception of westernmost Anatolia).

AMova showed that the majority of mtDNA variation $(84.09 \%)$ is distributed between the two clades of C. leucodon; only a small percentage of this variation

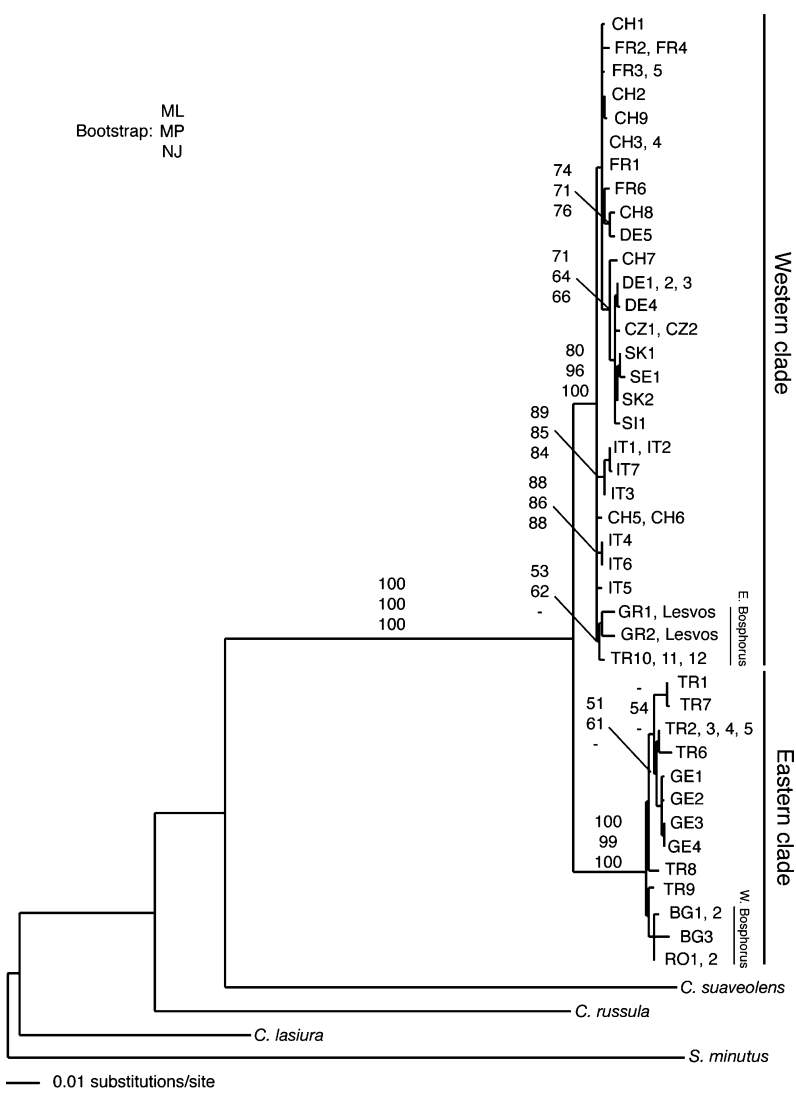

Fig. 2 Phylogeny of the 1077 bp cyt- $b$ fragment analysed with maximum likelihood, using the general time reversible model of substitution. Values in branches are indices of support for the major branches for maximum likelihood (ML), maximum parsimony (MP) and distance $(\mathrm{NJ})$ analyses (percentage of 1000 replications). Codes are as in Table 1.

$(15.91 \%)$ is observed within clades. Mean pairwise GTR distance between clades is $3.94 \%$. The mean pairwise GTR distances within clades and nucleotide diversities were $0.65 \%$ and 0.057 for the western clade, respectively, and $0.71 \%$ and 0.059 for the eastern clade.

Three additional sequences from Lesbos, Stymfalia, and Parnitha (Greece) described by Poulakakis et al. (2005) belong to the western clade, but were not included in our phylogenetic analyses. The analysis of these data (AY452166, AY452176, AY452165) revealed an unexpected result. The mean GTR distance between our samples and the Poulakakis et al. samples from Lesbos was $2.8 \%$. In comparing the sequences, we observed a large number of mutations at the beginning and end of their $c y t-b$ sequence. When the last $13 \mathrm{bp}$ of their sequence were deleted, the mean GTR distance fell to $0.89 \%$, and this was further reduced to $0.42 \%$ by deleting the first $48 \mathrm{bp}$ of their sequence (see Table 2 for the details of the mutations observed at the beginning and the end of the sequences of Poulakakis et al.). In addition, the mean GTR distance between the 
Table 2 Example of mutations observed between some of our samples and the samples of Poulakakis et al. (2005; *Lesvos, AY452165; Parnitha, AY452166; Stymfalia, AY452176).

\begin{tabular}{|c|c|c|c|c|c|c|c|c|c|c|c|c|c|c|c|c|c|c|c|}
\hline \multirow{2}{*}{$\frac{\text { Samples }}{\text { SK2, Bratislava }}$} & \multicolumn{19}{|c|}{ Example of mutations observed between sequences } \\
\hline & TC & TGC & ПТА & ATT & GCA & CAA & ATC & CTA & ACA & GGA & ПТА & $\pi \mathrm{C}$ & CTA & GCC & ATA & CAC & TAT & ACA & [53] \\
\hline 5, Serramazoni & . . & $\ldots$ & $\ldots$ & $\ldots$ & $\ldots$ & $\ldots$ & $\ldots$ & $\ldots$ & $\ldots$ & $\ldots$ & $\ldots$ & $\ldots$ & . & . & . & $\ldots$ & $\ldots$ & . & [53] \\
\hline & . & $\ldots$ & . & $\ldots$ & $\ldots$ & $\ldots$ & $\ldots$ & $\ldots$ & $\ldots$ & .. & $\ldots$ & $\ldots$ & . & $\ldots$ & & .. & $\ldots$ & & [53] \\
\hline & . & & $\ldots$ & $\ldots$ & & . & $\ldots$ & $\ldots$ & $\ldots$ & $\ldots$ & $\ldots$ & $\ldots$ & $\ldots$ & . & $\ldots$ & . . & $\ldots$ & $\ldots T$ & 3] \\
\hline & . & $\ldots$ & $\ldots$ & $\ldots$ & $\ldots$ & $\ldots$ & $\ldots$ & $\ldots$ & $\ldots$ & $\ldots$ & $\ldots$ & $\ldots$ & $\ldots$ & $\ldots$ & $\ldots$ & $\ldots$ & $\ldots$ & $\cdots$ & [53] \\
\hline & NN & NNN & NNN & NNN & NNN & $\ldots$ & $\ldots$ & $\ldots$ & $\ldots$ & $\ldots$ & $\ldots$ & $\ldots T$ & $\ldots$ & $\ldots$ & $\ldots$ & $\ldots$ & $\ldots$ & $\ldots T$ & [53] \\
\hline & NN & NNN & NNN & NNN & JNN & $\ldots$ & $\ldots$ & $\ldots G$ & . & $\ldots$ & $\ldots$ & $\ldots T$ & $\ldots$ & $\ldots$ & $\ldots$ & $\ldots$ & $\ldots$ & $\ldots$ & [53] \\
\hline & . & $\ldots$ & $\ldots$ & $\ldots$ & $\ldots$ & $\ldots$ & $\ldots$ & $\ldots T$ & $\ldots$ & $\ldots$ & C... & $\ldots T$ & $\ldots$ & $\ldots$ & $\ldots$ & $\ldots$ & $\ldots$ & $\ldots$ & [53] \\
\hline & . & $\ldots$ & $\ldots$ & . . & $\ldots$ & $\ldots$ & $\ldots$ & $\mathrm{T}$ & . & $\ldots$ & C.. & . & $\mathrm{T}$. & $\ldots$ & $\ldots$ & $\ldots$ & $\ldots$ & $\ldots$ & [53] \\
\hline & . & 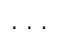 & $\ldots$ & $\ldots$ & $\ldots$ & $\ldots$ & $\ldots$ & $\mathrm{T}$ & $\ldots$ & $\ldots$ & C.. & $\ldots$ & $\ldots$ & $\ldots$ & $\ldots$ & $\ldots$ & $\ldots$ & $\ldots$ & [53] \\
\hline & TCT & GAT & ACT & $\mathrm{ACA}$ & $\mathrm{ACA}$ & GCT & TाC & TCC & TCC & GTA & $\mathrm{ACC}$ & CAT & ATT & TGC & CGA & GAT & GTA & AAT & 107] \\
\hline & . A & . & . & $\ldots$ & $\ldots$ & $\ldots$ & $\ldots$ & $\ldots$ & $\ldots$ & $\ldots$ & $\ldots$ & $\ldots$ & $\ldots$ & $\ldots$ & $\ldots$ & $\ldots$ & $\ldots$ & $\ldots$ & [107] \\
\hline & $\ldots \mathrm{A}$ & & $\ldots$ & $\ldots$ & $\ldots$ & $\ldots$ & $\ldots$ & $\ldots$ & $\ldots$ & $\ldots$ & $\ldots$ & $\ldots$ & $\ldots$ & $\ldots$ & $\ldots$ & . . & $\ldots$ & $\ldots$ & [107] \\
\hline & $\ldots A$ & & . & $\ldots$ & $\ldots$ & $\ldots$ & $\ldots$ & $\ldots$ & $\ldots$ & $\ldots$ & $\ldots$ & $\ldots$ & $\ldots$ & $\ldots$ & $\ldots$ & $\ldots$ & $\ldots$ & . & {$[107$} \\
\hline & $\therefore \mathrm{A}$ & & $\ldots$ & $\ldots$ & $\ldots$ & $\ldots$ & $\ldots$ & $\ldots$ & $\ldots$ & $\ldots$ & $\ldots$ & $\ldots$ & $\ldots$ & $\ldots$ & $\ldots$ & $\ldots$ & $\ldots$ & $\ldots$ & [107 \\
\hline & $\ldots A$ & & $\ldots$ & $\ldots$ & $\ldots$ & $\ldots$ & $\ldots$ & $\ldots$ & $\ldots$ & $\ldots$ & $\ldots$ & $\ldots$ & $\ldots$ & $\ldots$ & $\ldots$ & $\ldots$ & $\ldots$ & $\ldots$ & [107] \\
\hline & $\ldots A$ & & $\ldots C$ &. & $\ldots$ & $\ldots$ & $\ldots$ & . & $\ldots$ & $\ldots$ & $\ldots$ & $\ldots$ & $\ldots$ & $\ldots$ & $\ldots$ & $\ldots$ & $\ldots$ & $\cdots$ & [107] \\
\hline & $\ldots \mathrm{A}$ & & $\ldots C$ & $\ldots$ & & & & & & & $\ldots$ & & & $\ldots$ & $\ldots$ & & & & [107] \\
\hline & $\ldots A$ & & $\ldots$ & $\ldots$ & $\ldots$ & $\ldots$ & & $\ldots$ & $\ldots$ & & $\ldots$ & $\ldots$ & $\ldots$ & $\ldots$ & $\ldots$ & $\ldots$ & $\ldots$ & $\ldots$ & 07 \\
\hline & $\ldots \mathrm{A}$ & & & $\ldots$ & & $\ldots$ & $\ldots$ & $\ldots$ & $\ldots$ & $\ldots$ & $\ldots \mathrm{A}$ & $\ldots$ & $\ldots$ & $\ldots$ & $\ldots$ & $\ldots$ & $\ldots$ & $\ldots$ & [107 \\
\hline ava & TA & GGA & TAT & $\mathrm{GTT}$ & $\mathrm{C} \pi$ & $\mathrm{CCC}$ & TGA & GGT & CAA & ATA & TCA & $\pi$ & TGA & GGT & GCA & $\mathrm{ACA}$ & GTA & AT & [332] \\
\hline & . & $\ldots$ & $\ldots$ & $\ldots$ & $\ldots$ & $\ldots$ & $\ldots$ & $\ldots$ & $\ldots$ & $\ldots$ & $\ldots$ & $\ldots$ & $\ldots$ & $\ldots$ & $\ldots$ & $\ldots$ & $\ldots$ & $\ldots$ & [332] \\
\hline & . & $\ldots$ & $\ldots$ & . . & $\ldots$ & $\ldots$ & $\ldots$ & $\ldots$ & $\ldots$ & . & . & $\ldots$ & . & $\ldots$ & $\ldots$ & $\ldots$ & $\ldots$ & $\ldots$ & [332] \\
\hline & $\ldots$ & $\ldots$ & . & . & . & . & & $\ldots$ & $\ldots$ & & $\ldots$ & $\ldots$ & $\ldots$ & $\ldots$ & $\ldots$ & . & $\ldots$ & $\ldots$ & [332 \\
\hline & . . & . & $\ldots$ & $\ldots$ & & & . & $\ldots$ & . & & $\ldots$ & $\ldots$ & $\ldots$ & $\ldots$ & $\ldots$ & $\ldots$ & $\ldots$ & $\ldots$ & 332] \\
\hline & . & $\ldots$ & $\ldots$ & $\cdots$ & $\ldots$ & $\ldots$ & $\ldots$ & $\ldots A$ & & & & $\ldots C$ & & $\ldots G$ & $\ldots T$ & G. . & NNN & $\mathrm{NI}$ & 33 \\
\hline & . & $\ldots$ & $\ldots$ & $\ldots$ & $\ldots$ & $\ldots$ & $\ldots$ & $\ldots \mathrm{A}$ & . & $\ldots$ & $\ldots$ & $\ldots C$ & $\ldots$ & $\ldots G$ & $\ldots T$ & G. . & NNN & NN & 332 \\
\hline & . & $\ldots$ & $\ldots$ & . . & $\ldots$ & $\ldots$ & $\ldots$ & $\ldots A$ & $\ldots$ & $\ldots$ & $\ldots$ & $\ldots C$ & $\ldots$ & $\ldots G$ & $\ldots T$ & G. . & AGT & $\mathrm{T}$. & 332] \\
\hline 60 & . & $\ldots G$ & $\ldots$ & . & $\ldots$ & $\ldots$ & $\ldots$ & $\ldots$ & . & $\ldots$ & $\ldots$ & $\ldots$ & $\ldots$ & $\ldots$ & $\ldots$ & $\ldots$ & $\ldots$ & . & [332] \\
\hline GE1, Alazani & . & $\ldots G$ & $\ldots$ & $\ldots$ & $\ldots$ & $\ldots$ & $\ldots$ & $\ldots$ & $\ldots$ & $\ldots$ & $\ldots$ & $\ldots$ & $\ldots$ & $\ldots$ & . & $\ldots$ & $\ldots$ & . & [332] \\
\hline
\end{tabular}

Only the mutations including the first $107 \mathrm{bp}$ and the last $52 \mathrm{bp}$ of the Poulakakis sequences are shown. The samples SK2, IT5, TR10, GR1 and GR2 (this study) belong to the western mitochondrial clade, and the samples TR6 and GE1 from the eastern mitochondrial clade.

Poulakakis et al. samples from Lesvos and those from continental Greece was $2.15 \%$, whereas the mean distance between our samples from Lesbos and the Poulakakis et al. samples was $6.22 \%$; this value is still much greater than the mean GTR distance between all of our sequences from this clade $(0.65 \%)$ and the mean GTR distance between the two major clades (western and eastern) obtained in our analyses (3.94\%, Fig. 2).

A likelihood ratio test led to the acceptance of the molecular clock hypothesis for the whole sample $\left(\chi_{43}^{2}=\right.$ 53.44, $P=0.13)$-Ln Likelihood values with and without the molecular clock assumption are 4169.79 and 4143.07 , respectively, for the best trees. On the basis of the calibration of Fumagalli et al. (1999) and Dubey et al. (2006), we estimated the divergence time between the western and eastern clade to be $0.691 \mathrm{Myr}$ (95\% CI: 0.510-0.980; Fig. 2).

The IM model has six demographic parameters but we were particularly interested in three of them: $t$, the time of population splitting (in generation) in the past, and $m \mathrm{l}$ and $m 2$, the gene-flow rates per gene copy per generation. Once priors were correctly defined, we ran three runs for each clade. The different runs revealed unambiguous marginal posterior probability distributions of the parameters in each clade. The migration parameters revealed a peak at the lower limit of resolution in both directions (from East to West and vice versa) in both clades, as expected given that the Marmora Sea is a nonnegotiable barrier to dispersal once filled with water (during interglacials). We hereafter interpret the locations of these peaks as being at zero and then simulated three more runs for each clade fixing $m 1$ and $m 2$ to zero for estimating the time of the splits. The marginal posterior probability distribution of $t$ revealed a sharp peak at 0.525 and 1.785 for the Western and the Eastern clade respectively (Fig. 3). When converted to a scale of years, the divergence times between both sides of the Marmara Sea were estimated to be 17100 years $(90 \%$ HPD interval: 1700-40 600) for the Western clade, and 58200 years (90\% HPD interval: 16 100-109 000) for the Eastern one.

We observed a nonsignificant $P$-value for the mismatch distribution test of goodness-of-fit for the western clade (Harpending's Raggedness index $=0.02, \quad P=0.28$ ) 


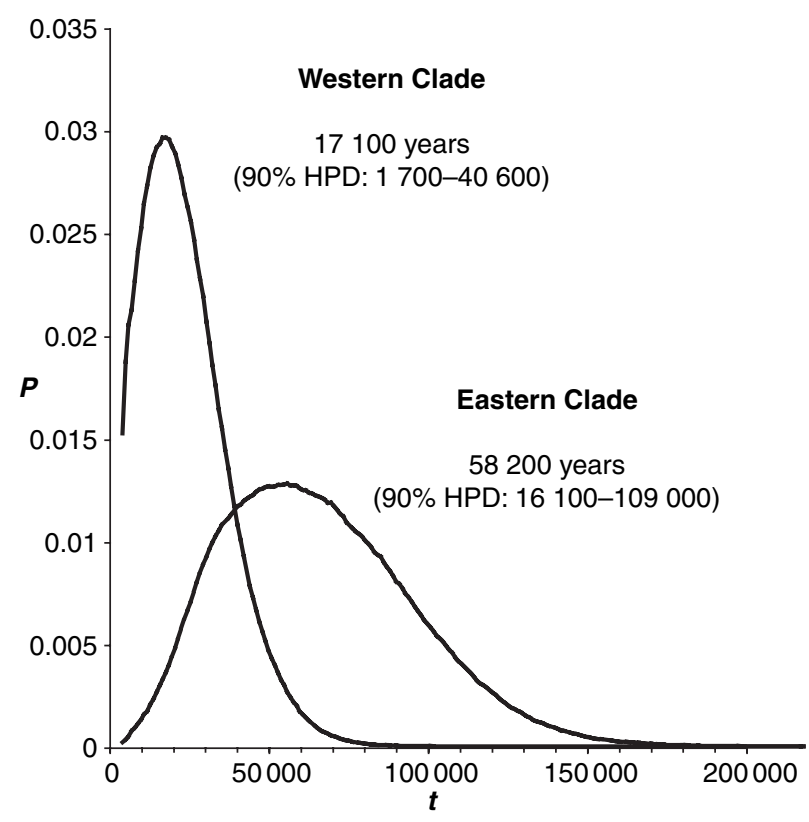

Fig. 3 Marginal posterior probability $(p)$ distribution of the divergence time parameter $(t)$ in year, from the isolation with migration model, between populations situated western and eastern of the Bosphorus Strait within the Western and Eastern Clade, and estimated time for the splits with the $90 \%$ highest posterior density (HPD) interval.

and a significant $P$-value for the eastern clade (Harpending's Raggedness index $=0.12, P=0.03$; Table 2). The frequency of the mean pairwise difference between haplotypes showed a bell-shaped distribution for the western clade, contrasting with the more complex distribution obtained for the eastern clade (Fig. 1). Fu's $F_{S}$ statistics and Tajima's $D$ were significant $\left(F_{S}=-10.68\right.$, $P<0.001 ; D=-1.48, P=0.04$; Table 3$)$ for the western clade but not significant for the eastern $\left(F_{S}=-2.02, P=\right.$ $0.16 ; D=-0.67, P=0.26)$; hence, we inferred a scenario of expansion for the western population and nonexpansion for the eastern population.

The timing of expansions was estimated from the mismatch distribution according to the method proposed by Rogers (1995; Fig. 1b,c). The $\tau$ value for the western population was 6.71 (95\% CI: 4.19-8.39). Assuming no saturation of uncorrected distances $(p)$, as shown in Dubey et al. (2006), the distance was 0.0612 per million years (95\% CI: 0.054-0.069). With a generation time of 1 year, the population expansion time was estimated to be 51900 years (95\% CI: 28 100-72 100).

\section{Apolipoprotein B gene}

The 44 analysed samples showed four different $A p o B$ alleles of $511 \mathrm{bp}$, named Al-A4 (Genbank accession: EF011555-EF011558), all the alleles differing from each others by only one mutation at the positions 62, 96 and 144 of our sequence alignment. Consequently, the different alleles of heterozygous samples were easily determined, as only one mutation was observed between alleles. The western mitochondrial clade samples were all homozygous for the allele Al (Table 1). In contrast, 13 Al homozygotes, two Al/A2 compound heterozygotes, one Al/A3 compound heterozygote, one Al/A4 compound heterozygote and one A4 homozygote were found in the eastern mitochondrial clade. This means that nucleotide diversities were 0.0000 for the western clade and 0.0006 for the eastern clade.

\section{Discussion}

\section{Quality of samples}

The integration of our $c y t-b$ sequences with those of Ohdachi et al. (2004); Fontanillas et al. (2005) and Dubey et al. (2006), analysed from preserved tissues, showed the expected genetic distances between samples. In contrast, the material of C. leucodon from owl pellets analysed by Poulakakis et al. (2005) showed GTR distances with our C. leucodon samples that were much higher than expected, even between samples from the same island (Lesbos; mean GTR distance: $2.8 \%$ ). A distance that fell to $0.42 \%$ by deleting the first and the last bp of their sequence from Lesbos. Moreover, no nonsynonymous mutations were observed in the cyt-b gene for our C. leucodon samples, whereas mutations at the end of the Poulakakis et al. (2005) sequences resulted in two amino acid substitu-

Table 3 Number of samples (Ns) and number of haplotypes (Nh) within the western and eastern mitochondrial bicoloured shrew clades, genetic diversity, nucleotide diversity, mean pairwise differences between haplotypes, Goodness-of-fit test probability, Fu's Fs test probability, Tajima's $D$ test probability, estimated $\tau$ value and expansion time for western clade.

\begin{tabular}{|c|c|c|c|c|c|c|c|c|c|}
\hline \multirow[b]{2}{*}{ Clade (Ns, Nh) } & \multirow{2}{*}{$\begin{array}{l}\text { Nucleotide div./ } \\
\text { mean pairwise diff. }\end{array}$} & \multicolumn{2}{|c|}{$\begin{array}{l}\text { Goodness-of-fit } \\
\text { test }\end{array}$} & \multicolumn{2}{|c|}{ Fu's Fs test } & \multicolumn{2}{|c|}{ Tajima's test } & \multirow[b]{2}{*}{$\tau$} & \multirow[b]{2}{*}{ Expansion time } \\
\hline & & Rag. Index & $P$ & Fs & $P$ & Tajima's D & $P$ & & \\
\hline Western $(34,23)$ & $0.0057 / 6.21$ & 0.02 & 0.28 & -10.68 & $<0.001$ & -1.48 & 0.04 & 6.80 (95\% Cl: 4.19-8.39) & $\begin{array}{l}51900 \text { years BP } \\
(95 \% \text { Cl: } 28100-72100)\end{array}$ \\
\hline Eastern $(16,11)$ & $0.0059 / 6.31$ & 0.12 & 0.03 & -2.02 & 0.16 & -0.67 & 0.26 & 7.47 (95\% Cl: 3.71-10.85) & - \\
\hline
\end{tabular}


tions; thus, these mutations appear to be highly suspect. These mutations may in fact be artefacts of DNA sequencing as a result of the poor template quality obtained from the owl pellets (Taberlet $\&$ Fumagalli, 1996; Waits \& Paetkau, 2005). This reinforces the value of repeating the DNA extraction and/or the analysis for each noninvasive sample several times in order to validate the sequencing result (Waits \& Paetkau, 2005). This means that the affirmation of Poulakakis et al. (2005) concerning the use of their samples for phylogenetic and phylogeographical studies of small mammals has to be questioned.

\section{Biogeography}

Based on our mitochondrial phylogenetic analyses, C. leucodon populations are divided in two main mitochondrial clades (mean GTR distance between clades: 3.94\%; Figs la and 2). The first clade (western clade) includes samples from western and central Europe, and unexpectedly, two samples from Lesbos Island and three from north-western Anatolia, to which the Greek samples (Lesbos, Parnitha and Stymfalia) from Poulakakis et al. (2005; results not shown) should be added. The second clade (eastern clade) includes samples from Bulgaria, Romania, Anatolia (with the exception of westernmost Anatolia) and Georgia. These two clades could represent the chromosomal differences observed between the Georgian samples and those from the Czech Republic and Lesbos that were detected in the karyotype analyses undertaken by Biltueva et al. (2001).

The separation between these two mitochondrial lineages of C. leucodon occurred in the Middle Pleistocene, 0.691 Myr (95\% CI: 0.510-0.980), the period immediately following the Günz glacial events (790 000-950 000 years $\mathrm{BP})$. This suggests the isolation of populations by submergence of the Bosphorus Strait (between the Black Sea and the Marmora Sea) with increasing sea levels following the glacial period.

Sedimentological and palaeontological evidence reveals that the Bosporus Strait has alternatively submerged and emerged since the Middle Pleistocene before being completely submerged from the Mid-Late Holocene (Kerey et al., 2004). Consequently, the fact that we observed a lack of clear structure between samples situated on either side of the Bosphorus Strait indicates that south-eastern Europe was probably colonized by the eastern mitochondrial lineages during a recent land bridge connection between Europe and the Near East (Late Pleistocene), a hypothesis confirmed by the migration analyses that estimated this event of vicariance to the Upper Pleistocene (58 200 years BP; 90\% HPD: 16 100-109 000). Based on similar results, the colonization of western Anatolia by the western mitochondrial lineage occurred during the same period (17 100 years BP; 90\% HPD: 1700-40 600; Late Pleistocene-Holocene). Thus, this strait appears to be a permeable biogeographic barrier for C. leucodon. This permeability has already been demonstrated in classical zoogeography for various species (e.g. Hosey, 1982) on the basis of unidirectional migrations from Europe to Anatolia (Hosey, 1982; Filippucci \& Simson, 1996; Kryštufek, 2002). However, our study demonstrates for the first time a Late PleistoceneHolocene bidirectional exchange of two different conspecific lineages between Europe and the Near East, whereas previous studies have only revealed unidirectional colonization.

The last climatic fluctuations of the Upper Pleistocene (126 000-11 500 years BP; Ogg, 2004) had contrasting impacts on the western and eastern mitochondrial clades. For the western clade, the bell-shaped curve of the mismatch distributions (Fig. lb) of the $c y t-b$ gene 0 [indicates an expansion following a bottleneck 50800 years ago (95\% CI: 28 100-72 100). This finding reveals that the last glacial maximum of the Pleistocene (22 000 years BP) had a moderate impact on these small mammal populations. Conversely, no sign of expansion was detected for the eastern mitochondrial clade of C. leucodon, which is consistent with the absence of nuclear polymorphism in the western clade $(\pi: 0.0000)$, whereas four alleles are present in the eastern $(\pi$ : 0.0006).

Thus, the European population appears to have been reduced to a small number of individuals during the last glaciations, probably confined to a small Italo-Balkanic refugium. Conversely, the eastern clade appears to have persisted with a greater population size and probably in several refugia around the Black Sea. This pattern has also been suggested for mammals and plants (Michaux et al., 2004; Heuertz et al., 2006; Kučera et al., 2006), based on a higher genetic diversity observed in Anatolian populations compared with European ones. Moreover, these results are also supported by palynological data that indicate that open wooded cover in this area persisted through the full glacial condition of the Pleistocene (Tarasov et al., 2000).

\section{Conclusion}

Based on molecular data, we confirmed that the Bosporus Strait was a permeable barrier. This finding has been suggested previously by the colonization of western Anatolia by European populations of the lesser whitetoothed shrew in the Lower Pleistocene (C. suaveolens; Dubey et al., 2006) and more recently by the hedgehog (Filippucci \& Simson, 1996; Kryštufek, 2002). Moreover, we provide evidence that European populations of the bicoloured shrew may be the source of recent West Anatolian populations.

We also found a marked difference in population history between the two divergent mitochondrial lineages of bicoloured shrew, suggesting that Pleistocene climatic variations have more strongly reduced the genetic diversity of the European population than that 
of the Near East population. We hypothesize that this could be a general pattern for fauna and flora, as other studies comparing these geographical areas have reported similar differences (Michaux et al., 2004; Heuertz et al., 2006; Kučera et al., 2006).

\section{Acknowledgments}

We thank N. Di Marco for laboratory facilities, C. Ohayon for scientific and linguistic advice and M. Fontaine for noticeable advice in using IM software. We are grateful to P. Borkenhagen, P. Brunnet-Lecompte, H. Brünner, F. Catzeflis, P. Müller, R. Parapanov, C. Vogel and M. Zaitsev for tissues samples, and to A. Andreeva, S. Uzunov (Bulgaria), C. Kurtonur (Turkey), D. Murariu (Romania) for integrating us (PV) in local fieldwork for trapping shrews. The study was partly sponsored by GACR (grant 206/05/2334) and MSMT CR (project $0021620828)$.

\section{References}

Bilton, D.T., Mirol, P.M., Mascheretti, S., Fredga, K., Zima, J. \& Searle, J.B. 1998. Mediterranean Europe as an area of endemism for small mammals rather than a source for northwards postglacial colonization. Proc. R. Soc. Lond., Ser. B Biol. Sci. 265: 1219-1226.

Biltueva, L.S., Rogatcheva, M.B., Perelman, P.L., Borodin, P.M., Oda, S.I., Koyasu, K., Harada, M., Zima, J. \& Graphodatsky, A.S. 2001. Chromosomal phylogeny of certain shrews of the genera Crocidura and Suncus (Insectivora). J. Zool. Syst. Evol. Res. 39: 69-76.

Brändli, L., Handley, L.J., Vogel, P. \& Perrin, N. 2005. Evolutionary history of the greater white-toothed shrew (Crocidura russula) inferred from analysis of mtDNA, Y and X chromosome markers. Mol. Phylogenet. Evol. 37: 832-844.

Cooper, S.J.B., Ibrahim, K.M. \& Hewitt, G.M. 1995. Postglacial expansion and genome subdivision in the European Grasshopper Chorthippus parallelus. Mol. Ecol. 4: 49-60.

Culling, M.A., Janko, K., Boron, A., Vasil'ev, V.P., Cote, I.M. \& Hewitt, G.M. 2006. European colonization by the spined loach (Cobitis taenia) from Ponto-Caspian refugia based on mitochondrial DNA variation. Mol. Ecol. 15: 173-190.

Dubey, S., Zaitsev, M., Cosson, J.-F., Abdukadier, A. \& Vogel, P. 2006. Pliocene and Pleistocene diversification and multiple refugia in a Eurasian shrew (Crocidura suaveolens group). Mol. Phylogenet. Evol. 38: 635-647.

Dubey, S., Cosson, J.-F., Magnanou, E, Vohralík, V., Benda, P., Frynta, D., Hutterer, R., Vogel, V. \& Vogel, P. 2007a. Mediterranean populations of the lesser white-toothed shrew (Crocidura suaveolens group): an unexpected puzzle of Pleistocene survivors and prehistoric introductions. Mol. Ecol. in press.

Dubey, S., Salamin, N., Ohdachi, S.D., Barriere, P. \& Vogel, P. 2007b. Molecular phylogenetics of shrews (Mammalia: Soricidae) reveal timing of transcontinental colonizations. Mol. Phylogenet. Evol. 44: 126-137.

Dumolin-Lapegue, S., Demesure, B., Fineschi, S., LeCorre, V. \& Petit, R.J. 1997. Phylogeographic structure of white oaks throughout the European continent. Genetics 146: 1475-1487.
Ferris, C., Oliver, R.P., Davy, A.J. \& Hewitt, G.M. 1993. Native oak chloroplasts reveal an ancient divide across Europe. Mol. Ecol. 2: 337-344.

Ferris, C., King, R.A., Vainola, R. \& Hewitt, G.M. 1998. Chloroplast DNA recognizes three refugial sources of European oaks and suggests independent eastern and western immigrations to Finland. Heredity 80: 584-593.

Filippucci, M.G. \& Simson, S. 1996. Allozyme variation and divergence in Erinaceidae (Mammalia, Insectivora). Isr. J. Zool. 42: 335-345.

Fontanillas, P., Depraz, A., Giorgi, M.S. \& Perrin, N. 2005. Nonshivering thermogenesis capacity associated to mitochondrial DNA haplotypes and gender in the greater whitetoothed shrew, Crocidura russula. Mol. Ecol. 14: 661-670.

Fu, Y.X. 1997. Statistical tests of neutrality of mutations against population growth, hitchhiking and background selection. Genetics 147: 915-925.

Fumagalli, L., Taberlet, P., Stewart, D.T., Gielly, L., Hausser, J. \& Vogel, P. 1999. Molecular phylogeny and evolution of Sorex shrews (Soricidae: Insectivora) inferred from mitochondrial DNA sequence data. Mol. Phylogenet. Evol. 11: 222-235.

Guindon, S. \& Gascuel, O. 2003. A simple, fast, and accurate algorithm to estimate large phylogenies by maximum likelihood. Syst. Biol. 52: 692-704.

Heuertz, M., Carnevale, S., Fineschi, S., Sebastiani, F., Hausman, F., Paule, L. \& Vendramin, G.G. 2006. Chloroplast DNA phylogeography of European ashes, Fraxinus sp. (Oleaceae): roles of hybridization and life history traits. Mol. Ecol. 15: 2131-2140.

Hewitt, G.M. 1999. Post-glacial re-colonization of European biota. Biol. J. Linn. Soc. 68: 87-112.

Hewitt, G.M. 2000. The genetic legacy of the quaternary ice ages. Nature 405: 907-913.

Hewitt, G.M. 2004a. Genetic consequences of climatic oscillations in the Quaternary. Phil. Trans. R. Soc. Lond. Ser. B. 359 : 183-195.

Hewitt, G.M. 2004b. The structure of biodiversity - insights from molecular phylogeography. Front. Zool. 1: 4.

Hey, J. 2007. Using the IM program, IM Documentation. http:// lifesci.rutgers.edu/ heylab/ProgramsandData/Programs/IM/ Using_IM_3_5_2007.pdf.

Hosey, G.R. 1982. The Bosporus land-bridge and mammal distributions in Asia Minor and the Balkans. Säugetierkd. Mitt. 30: $53-62$.

Irwin, D.M., Kocher, T.D. \& Wilson, A.C. 1991. Evolution of the cytochrome $b$ gene of Mammals. J. Mol. Evol. 32: 128-144.

Kerey, I.E., Meric, E., Kelling, G., Brenner, R.A. \& Dogan, A.U. 2004. Black Sea-Marmara Sea Quaternary connections: new data from the Bosphorus, Istanbul, Turkey. Paleogeogr. Paleocl. Paleoecol. 204: 277-295.

Koch, M.A., Kiefer, C., Ehrich, D., Vogel, J., Brochmann, C. \& Mummenhoff, K. 2006. Three times out of Asia Minor: the phylogeography of Arabis alpina L. (Brassicaceae). Mol. Ecol. 15: $825-839$.

Kryštufek, B. 2002. Cranial variability in the eastern hedgehog Erinaceus concolor (Mammalia: Insectivora). J. Zool. (London) 258: 365-373.

Kučera, J., Líhová, J. \& Marhold, K. 2006. Taxonomy and phylogeography of Cardamine impatiens and C. pectinata (Brassicaceae). Bot. J. Linn. Soc. 152: 169-195.

Marmi, J., Lopez-Giraldez, F., MacDonald, D.W., Calafell, F., Zholnerovskaya, E. \& Domingo-Roura, X. 2006. Mitochond- 
rial DNA reveals a strong phylogeographic structure in the badger across Eurasia. Mol. Ecol. 15: 1007-1020.

Michaux, J.R., Libois, R., Paradis, E. \& Filippucci, M.G. 2004. Phylogeographic history of the yellow-necked fieldmouse (Apodemus flavicollis) in Europe and in the Near and Middle East. Mol. Phylogenet. Evol. 32: 788-798.

Nesbo, C.L., Fossheim, T., Vollestad, L.A. \& Jakobsen, K.S. 1999. Genetic divergence and phylogeographic relationships among European perch (Perca fluviatilis) populations reflect glacial refugia and postglacial colonization. Mol. Ecol. 8: 1387-1404.

Nielsen, R. \& Wakeley, J. 2001. Distinguishing migration from isolation: a Markov chain Monte Carlo approach. Genetics 158 : 885-896.

Ogg, J.G. 2004. Status of divisions of the International Geologic Time Scale. Lethaia 37: 183-199.

Ohdachi, S.D., Iwasa, M.A., Nesterenko, V.A., Abe, H., Masuda, R. \& Haberl, W. 2004. Molecular phylogenetics of Crocidura shrews (Insectivora) in east and central Asia. J. Mammal 85: 396-403.

Palme, A.E. \& Vendramin, G.G. 2002. Chloroplast DNA variation, postglacial recolonization and hybridization in hazel, Corylus avellana. Mol. Ecol. 11: 1769-1780.

Parker, S.R., 1997. Sequence Navigator. Multiple sequence alignment software. Methods Mol. Biol. 70: 145-154.

Posada, D. \& Crandall, K.A. 1998. modeltest: testing the model of DNA substitution. Bioinformatics 14: 817-818.

Poulakakis, N., Lymberakis, P., Paragamian, K. \& Mylonas, M. 2005. Isolation and amplification of shrew DNA from barn owl pellets. Biol. J. Linn. Soc. 85: 331-340.

Rodriguez, R., Oliver, J.L., Marin, A. \& Medina, J.R. 1990. The general stochastic model of nucleotide substitution. J. Theor. Bio. 142: 485-501.

Rogers, A.R. 1995. Genetic-evidence for a Pleistocene population explosion. Evolution 49: 608-615.

Santucci, F., Emerson, B.C. \& Hewitt, G.M. 1998. Mitochondrial DNA phylogeography of European hedgehogs. Mol. Ecol. 7: 1163-1172.

Schneider, I. 2000. Software programs for DNA sequence analysis. Genet. Eng. News 20: 8.

Schneider, S. \& Excoffier, L. 1999. Estimation of past demographic parameters from the distribution of pairwise differences when the mutation rates vary among sites: Application to human mitochondrial DNA. Genetics 152: 1079-1089.

Seddon, J.M., Santucci, F., Reeve, N. \& Hewitt, G.M. 2002. Caucasus Mountains divide postulated postglacial colonization routes in the white-breasted hedgehog, Erinaceus concolor. J. Evol. Biol. 15: 463-467.

Swofford, D.L. 1998. PAuP*. Phylogenetic Analysis Using Parsimony (* and other Methods). Version 4.0bl. Sinauer Associates, Sunderland, MA, USA.

Taberlet, P. \& Fumagalli, L. 1996. Owl pellets as a source of DNA for genetics studies of small mammals. Mol. Ecol. 5: 301-305.

Taberlet, P., Fumagalli, L., Wust-Saucy, A.G. \& Cosson, J.F. 1998. Comparative phylogeography and postglacial colonization routes in Europe. Mol. Ecol. 7: 453-464.

Tajima, F. 1989. Statistical method for testing the neutral mutation hypothesis by DNA polymorphism. Genetics 123: 585-595.

Tarasov, P.E., Volkova, V.S., Webb, T., Guiot, J., Andreev, A.A., Bezusko, L-G., Bezusko, T.V., Bykova, G.V., Dorofeyuk, N.I., Kvavadze, E.V., Osipova, I.M., Panova, N.K. \& Sevastyanov, D.V. 2000. Last glacial maximum biomes reconstructed from pollen and plant macrofossil data from northern Eurasia. J. Biogeogr. 27: 609-620.

Thorpe, R.S. 1984. Primary and secondary transition zones in speciation and population differentiation - a phylogenetic analysis of range expansion. Evolution 38: 233-243.

Vogel, P., Cosson, J.F. \& Jurado, L.F.L. 2003. Taxonomic status and origin of the shrews (Soricidae) from the Canary Islands inferred from a mtDNA comparison with the European Crocidura species. Mol. Phylogenet. Evol. 27: 271-282.

Vörös, J., Alcobendas, M., Martinez-Solano, I. \& Garcia-Paris, M. 2006. Evolution of Bombina bombina and Bombina variegata (Anura: Discoglossidae) in the Carpathian Basin: a history of repeated mt-DNA introgression across species. Mol. Phylogenet. Evol. 38: 705-718.

Waits, L.P. \& Paetkau, D. 2005. Noninvasive genetic sampling tools for wildlife biologists: a review of applications and recommendations for accurate data collection. J. Wildl. Manage. 69: 1419-1433.

Received 14 February 2007; revised 28 April 2007; accepted 2 May 2007 